University of Nebraska - Lincoln

DigitalCommons@University of Nebraska - Lincoln

$11-1-1994$

\title{
Nanostructures of Sm-Co on Cr thin films
}

Yi Liu

University of Nebraska-Lincoln, yliu@unl.edu

B. W. Robertson

University of Nebraska-Lincoln, brobertson1@unl.edu

Z.S. Shan

University of Nebraska - Lincoln

S. Malhotra

University of Nebraska - Lincoln

M.J. Yu

University of Nebraska - Lincoln

See next page for additional authors

Follow this and additional works at: https://digitalcommons.unl.edu/physicsliou

Part of the Physics Commons

Liu, Yi; Robertson, B. W.; Shan, Z.S.; Malhotra, S.; Yu, M.J.; Renukunta, S.K.; Liou, Sy_Hwang; and Sellmyer, David J., "Nanostructures of Sm-Co on Cr thin films" (1994). Si-Hwang Liou Publications. 58.

https://digitalcommons.unl.edu/physicsliou/58

This Article is brought to you for free and open access by the Research Papers in Physics and Astronomy at DigitalCommons@University of Nebraska - Lincoln. It has been accepted for inclusion in Si-Hwang Liou Publications by an authorized administrator of DigitalCommons@University of Nebraska - Lincoln. 
Authors

Yi Liu, B. W. Robertson, Z.S. Shan, S. Malhotra, M.J. Yu, S.K. Renukunta, Sy_Hwang Liou, and David J. Sellmyer 


\title{
LOW TEMPERATURE PHASE FORMATION OF TL-BASED SUPERCONDUCTING THIN FILMS IN REDUCED OXYGEN ATMOSPHERE.
}

\author{
C. Y. Wu", F. Foong and S. H. Liou \\ Behlen Laboratory of Physics and \\ Center for Materials Research and Analysis \\ University of Nebraska-Lincoln \\ Lincoln, NE 68588 \\ J. C. Ho \\ Department of Physics and \\ National Institute for Aviation Research \\ Wichita State University \\ Wichita, KS 67208
}

\begin{abstract}
Tl-Ba-Ca-Cu-O superconducting thin films were prepared by magnetron sputtering with post-annealing in a reduced oxygen atmosphere. Single phase $\mathrm{Tl}_{2} \mathrm{Ba}_{2} \mathrm{Ca}_{2} \mathrm{Cu}_{3} \mathrm{O}_{\mathrm{x}}$ can form on the $\mathrm{MgO}$ substrate at $800^{\circ} \mathrm{C}$ under $\mathrm{P}\left(\mathrm{O}_{2}\right) \approx 0.1 \mathrm{~atm}$. However the phase formation temperature can be affected by the starting composition of the film. $\mathrm{Tl}_{1} \mathrm{Ba}_{2} \mathrm{Ca}_{2} \mathrm{Cu}_{3} \mathrm{O}_{\mathrm{x}}$ phase can be formed by simply lowering the $\mathrm{Tl}_{2} \mathrm{O}$ pressure. The thermal stability of $\mathrm{Tl}_{2} \mathrm{Ba}_{2} \mathrm{Ca}_{2} \mathrm{Cu}_{3} \mathrm{O}_{\mathbf{x}}$ phase was studied by resistivity measurements at high temperatures.
\end{abstract}

\section{INTRODUCTION}

Since the discovery of superconductivity in the Tl-Ba$\mathrm{Ca}-\mathrm{Cu}-\mathrm{O}$ system,[1] several phases have been identified[2][3] and most of them have superconducting transition temperatures $\left(\mathrm{T}_{\mathrm{c}}\right)$ above the normal boiling point of liquid nitrogen. The $\mathrm{T}_{\mathrm{c}}$ of $\mathrm{Tl}_{2} \mathrm{Ba}_{2} \mathrm{Ca}_{2} \mathrm{Cu}_{3} \mathrm{O}_{x}$ (Tl-2223) remains the highest found so far. However, due to the difficulty in the material synthesis, the properties of the thallium compounds are least known compared to $\mathrm{YBa}_{2} \mathrm{Cu}_{3} \mathrm{O}_{7-\delta}$ and bismuth-compounds. No suitable phase diagram is available yet partly due to the volatility and toxicity of thallium. The rapid loss of thallium during annealing further complicates the thin film preparation process.

There have been a limited number of studies on the effects of oxygen pressure during synthesis. It was demonstrated that high pressure annealing can suppress the thallium loss.[4] Annealing in vacuum was also used in the synthesis of bulk samples and a $T_{c}$ of $127 \mathrm{~K}$ was reported for the 2223 phase[5]. Vacuum annealing may have the advantage of lowering the processing temperature, which is beneficial to the thin film fabrication. As previously reported, under one atmosphere pressure, thin films of the

This work was supported by the NASA Lewis Grant NAG 3-886.

* Present address: National Institute for Aviation Research, Cryogenics Lab, Wichita State University, Wichita, KS 67208.

Manuscript received August 24, 1992.
Tl-2223 superconductor can be obtained with $T_{c}$ above $120 \mathrm{~K}$ by annealing at $880^{\circ} \mathrm{C}-900^{\circ} \mathrm{C}$ [ [6][7] However, this high temperature annealing may induce film surface roughness and cause film-substrate interactions. Nevertheless, under vacuum, the annealing temperature can be greatly reduced and smoother films can be obtained [8]

In this work, we have investigated the growth of the thallium-based superconducting thin films under low oxygen pressure. The thermal stability of the T1-2223 phase was also studied using thermoelectrometry.

\section{VACUUM ANNEALING}

Thin films were deposited on (001) surfaces of $\mathrm{LaAlO}_{3}$ and $\mathrm{MgO}$ substrates by RF-magnetron sputtering from sintered targets of $\mathrm{Ba}-\mathrm{Ca}-\mathrm{Cu}-\mathrm{O}$. The details have been reported previously.[6] The sputtering targets were made from high purity $\mathrm{BaF}_{2}, \mathrm{CaO}$ and $\mathrm{CuO}$. Annealing was done in an O-ring sealed ceramic tube where the film was wrapped in gold foil with a $\mathrm{Tl}-\mathrm{Ba}-\mathrm{Ca}-\mathrm{Cu}-\mathrm{O}$ compound to supply thallium and maintain the $\mathrm{Tl}_{2} \mathrm{O}$ pressure. Before annealing, the tube was evacuated and the pressure was estimated to be less than $0.1 \mathrm{~atm}$ X-ray diffraction was used to analyze the phase formation.

Figure 1 shows the x-ray $\theta-2 \theta$ scans of two films on $\mathrm{MgO}$ substrates annealed in vacuum at two different temperatures, $790^{\circ} \mathrm{C}$ and $800^{\circ} \mathrm{C}$. The $(00 \mathrm{e})$ peaks of the 2223 phase and 2212 phase are marked in Figure 1 (a) and (b), respectively. As can be seen from the figure, annealing at $800^{\circ} \mathrm{C}$ yielded a nearly single 2223 phase and nighly textured film. Below that temperature, $\mathrm{Tl}_{2} \mathrm{Ba}_{2} \mathrm{Ca}_{1} \mathrm{Cu}_{2} \mathrm{O}_{\mathrm{x}}$ (2212) phase started to emerge. The starting composition of these films was $2 \mathrm{Ba}: 2 \mathrm{Ca}: 3 \mathrm{Cu}$. The formation of 2223 phase could be different for different starting compositions. For example, for the composition of $2 \mathrm{Ba}: 2.4 \mathrm{Ca}: 3 \mathrm{Cu}$, pure 2223 phase was obtained by annealing above $830^{\circ} \mathrm{C}$ in vacuum.

The phase formation is also affected by the $\mathrm{T}_{2} \mathrm{O}$ pressure during annealing. With a lower $\mathrm{Tl}_{2} \mathrm{O}$ pressure, $\mathrm{Tl}_{1} \mathrm{Ba}_{2} \mathrm{Ca}_{2} \mathrm{Cu}_{3} \mathrm{O}_{\mathrm{x}}$ (1223) phase was formed under the same 


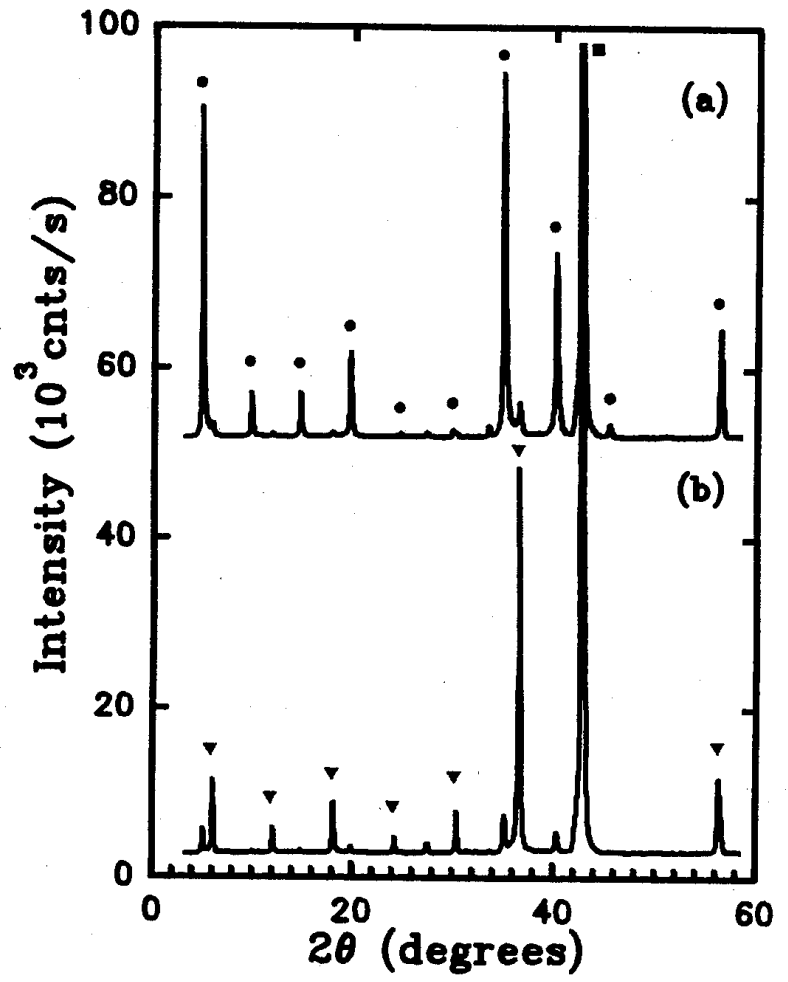

Fig. 1 X-ray diffraction patterns of Tl-Ba-Ca-Cu-O films on $\mathrm{MgO}(001)$ substrate. (a) annealed at $800^{\circ} \mathrm{C}$ (b) annealed at $790^{\circ} \mathrm{C}$. (00 $)$ peaks are identified by $(\bullet)$ for 2223 phase and $(v)$ for 2212 phase. (•) for $\mathrm{MgO}$.

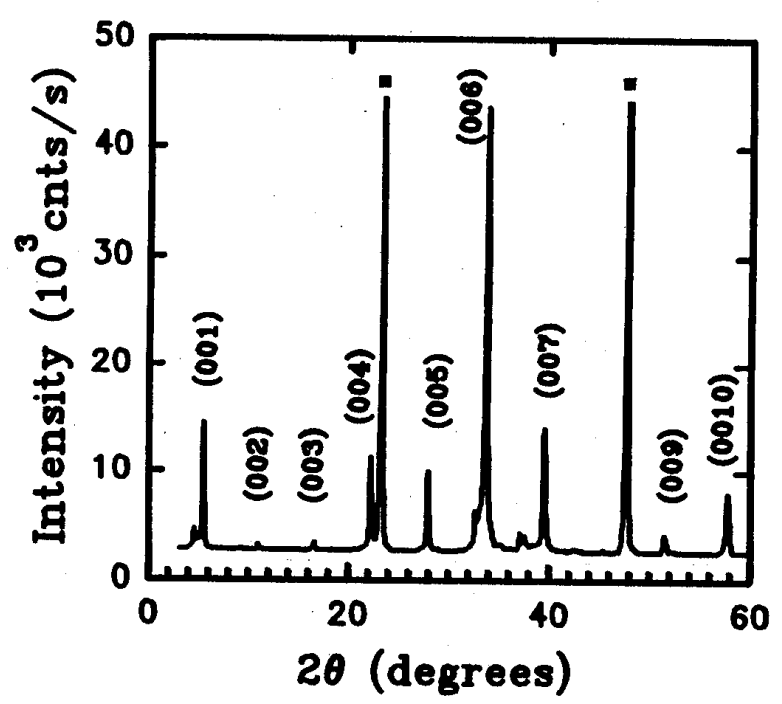

Fig. 2 X-ray diffraction pattern showing Tl-1223 phase. (00 $)$ peaks are labeled. (*) peaks are from $\mathrm{LaAlO}_{3}$ substrate. annealing condition and starting composition as for T1-2223 films. The x-ray diffraction pattern of such a film grown on a $\mathrm{LaAlO}_{3}$ substrate is shown in Figure 2. The major diffraction peaks can be assigned to (00 $)$ ) of the 1223 phase. The $\mathrm{Tl}_{2} \mathrm{O}$ pressure was controlled by varying the composition and processing of the compensating thallium compound.

The films annealed at low temperature under low oxygen pressure are generally smoother than those annealed at high temperature under ambient pressure. However, the growth behaviors are similar. An SEM graph of the 1223 film on $\mathrm{LaAlO}_{3}$ obtained by vacuum annealing is given in Figure 3. Platelike growth can be easily identified in this figure. The particles on the top of the plates have calcium rich (small particles) and barium rich (large particles) composition.

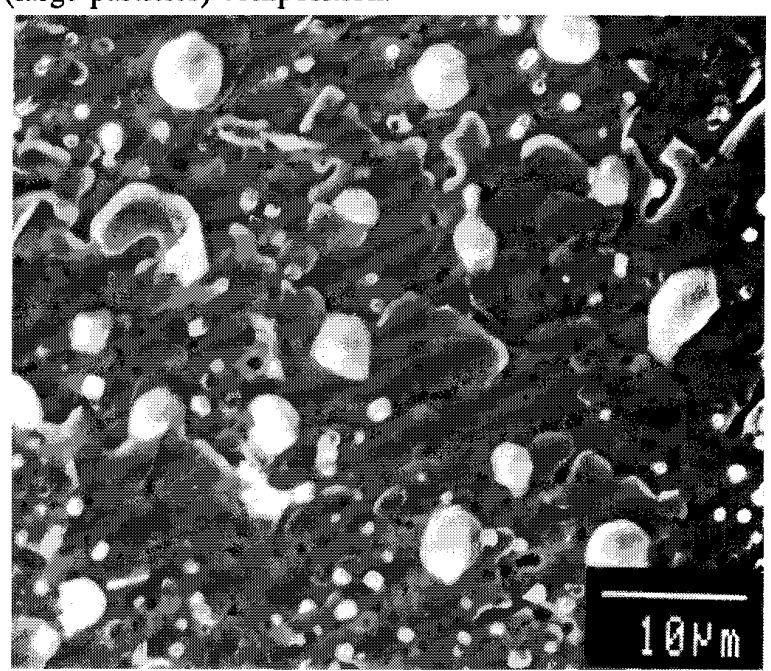

Fig. 3 SEM graph of a Tl-1223 film annealed at $810^{\circ} \mathrm{C}$ in vacuum.

\section{THERMOELECTROMETRY}

In further studying the thermal stability of the Tl-2223 compound, resistance was measured as the sample was heated to elevated temperatures. Measurements were done in a vacuum chamber and the sample was mounted to a stainless-steel block with a quartz lamp inside as a heater. A temperature sensor (thermocouple) was inserted into the stainless steel block near the sample. Two gold electrodes were deposited on the sample for two-point resistance measurement, and silver paste was used to attach copper leads to the electrodes. The contact resistance was wellbehaved throughout the temperature range under study. The contact plus wire resistance was about $1 \Omega$ at room temperature and increased slightly as the temperature went up; but no anomaly was observed. The validity of the measurement was confirmed by repeated measurements on different samples under the same conditions. 


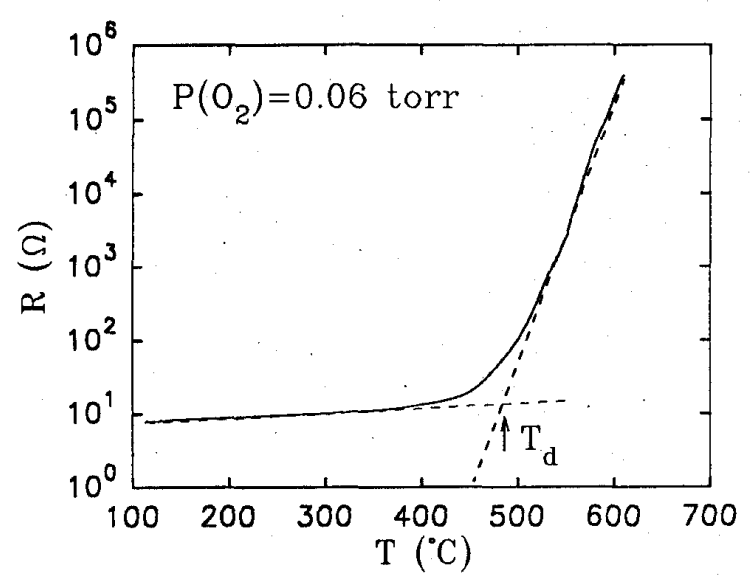

Fig. 4 R-T trace of a Tl-2223 film. Heating rate $=5^{\circ} \mathrm{C} / \mathrm{min}$.

The Tl-2223 films used in this measurement were $2 \mu \mathrm{m}$. thick. A heating rate of $5 \circ \mathrm{C} / \mathrm{min}$ was used. Figure 4 shows an R-T trace measured in 0.06 torr of oxygen pressure. As seen in the figure, as the temperature increases, the resistance increases slightly initially, and this is followed by a drastic rise at about $T_{d}=480^{\circ} \mathrm{C}$. This rapid change of resistance should correspond to the thallium activity in the film, probably the out-diffusion of thallium. The measured $\mathrm{T}_{\mathrm{d}}$ 's are plotted against the oxygen pressure in Figure 5. They fall into a straight line in semi-log scale. This line is close to the T1-2223 phase stability line given in Ref [9].

The results obtained by this kind of resistivity measurement may be affected by the film thickness and grain boundary configuration. But together with other thermal analysis techniques, such as TGA and DTA, they should provide crucial information for guiding material synthesis. Also this simple method can be used for in situ monitoring of thin film growth.

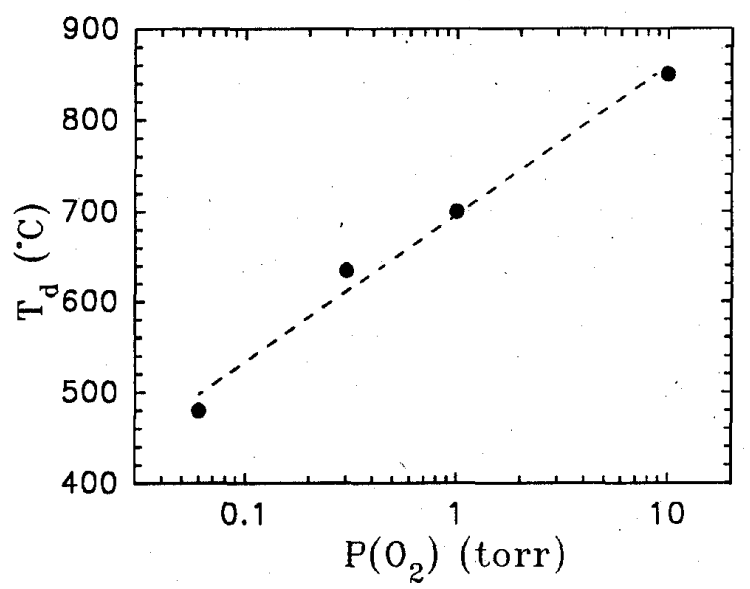

Fig. $5 T_{d}$ versus oxygen pressure $\mathrm{P}\left(\mathrm{O}_{2}\right)$.

\section{SUMMARY}

Single phase $\mathrm{Tl}_{2} \mathrm{Ba}_{2} \mathrm{Ca}_{2} \mathrm{Cu}_{3} \mathrm{O}_{\mathrm{x}}$ can form on the $\mathrm{MgO}$ substrate at $800^{\circ} \mathrm{C}$ under $\mathrm{P}\left(\mathrm{O}_{2}\right) \approx 0.1$ atm. For calcium rich compositions, the phase formation temperature is higher. The $\mathrm{Tl}_{1} \mathrm{Ba}_{2} \mathrm{Ca}_{2} \mathrm{Cu}_{3} \mathrm{O}_{\mathrm{x}}$ phase can be formed by simply lowering the $\mathrm{Tl}_{2} \mathrm{O}$ pressure. The temperature at which thallium is lost from $\mathrm{Tl}_{2} \mathrm{Ba}_{2} \mathrm{Ca}_{2} \mathrm{Cu}_{3} \mathrm{O}_{\mathrm{x}}$ significantly is proportional to the logarithm of oxygen pressure.

\section{REFERENCES}

[1] Z. Z. Sheng and A. M. Hermann, "Superconductivity in the rare-earth-free $\mathrm{Tl}-\mathrm{Ba}-\mathrm{Cu}-\mathrm{O}$ system above liquidnitrogen temperature", Nature vol. 332, pp. 55-58, Mar. 1988; "Bulk Superconductivity at $120 \mathrm{~K}$ in the $\mathrm{Tl}-\mathrm{Ca} / \mathrm{Ba}-\mathrm{Cu}-\mathrm{O}$ system", Nature vol. 332, pp. 138-139, Mar. 1988.

[2] R. M. Hazen, L. W. Finger, R. J. Angel, C. T. Prewitt, N. L. Ross, C. G. Hadidiacos, P. J. Heaney, D. R. Veblen, Z. Z. Sheng, A. El Ali, and A. M. Hermann, "100-K superconducting phases in the T-Ca-Ba-Cu-O system", Phys. Rev. Lett. vol, 60, pp. 1657-1660, Apr. 1988.

[3] S. S. P. Parkin, V. Y. Lee, A. I. Nazzal, R. Savoy, R. Beyers, and S. J. La Placa, $\mathrm{Tl}_{1} \mathrm{Ca}_{\mathrm{n}-1} \mathrm{Ba}_{2} \mathrm{Cu}_{\mathrm{n}} \mathrm{O}_{2 \mathrm{n}+3}$ $(\mathrm{n}=1,2,3)$ : a new class of crystal structures exhibiting volume superconductivity at up to $\approx 110 \mathrm{~K}^{\prime}$, Phys. Rev. Lett. vol. 61, pp. 750-753, Aug 1988.

[4] D. E. Morris, M. R. Chandrachood, and A P. B. Sinha, "Synthesis of high quality thallium superconductors at elevated oxygen pressure", Physica $C$ vol. 175 , pp. $156-164,1991$.

[5] T. Kaneko, H. Yamauchi and S. Tanaka, Zeroresistance temperature of $T 1$ based 12223 " superconductor increased to $127 \mathrm{~K}^{\prime \prime}$, Physica $\mathrm{C}$ vol 178, pp. 377-382, 1991.

[6] S. H. Liou, V. K. Chan, F. Foong, W. Y. Lee, Y S Gou and T. M. Uen, Synthesis and superconducting properties of Tl-Ba-Ca-Cu-O films", IEEE Trans, Mag vol. 27, pp. 1227-1230, Mar. 1991.

[7] W. Y. Lee, J. Vazquez, T. C. Huang, and R. Savoy, "120-K Tl-based high- $\mathrm{T}_{\mathrm{c}}$ superconducting thin films on $\mathrm{LaAlO}_{3}$ substrates", J. Appl. Phys. vol. 70, pp. 3952 3954, Oct. 1991.

[8] W. Y. Lee, S. M. Garrison, M. Kawasaki, E. L. Venturini, B. T. Ahn, R. Beyers, J. Salem, R. Savoy and J. Vazquez, "Low-temperature formation of expitaxial $\mathrm{Tl}_{2} \mathrm{Ca}_{2} \mathrm{Ba}_{2} \mathrm{Cu}_{3} \mathrm{O}_{10}$ thin films in reduced $\mathrm{O}_{2}$ pressure", Appl. Phys. Lett. vol. 60, pp. 772-774, Feb. 1992.

[9] B. T. Ahn, W. Y. Lee and R. Beyers, Effect of oxygen pressure on $\mathrm{Tl}_{2} \mathrm{Ca}_{2} \mathrm{Ba}_{2} \mathrm{Cu}_{3} \mathrm{O}_{10 \pm \delta}$ formation", Appl. Phys. Lett. vol. 60, pp. 2150-2152, Apr. 1992. 